\title{
The role of internationalisation in students' cultural literacy and intercultural communication
}

\author{
Alina Romanovska ${ }^{1}$, Irina Presnakova ${ }^{2}$ \\ ${ }^{1}$ Institute of the Humanities and Social Sciences, Daugavpils University, Latvia, ${ }^{2}$ Department \\ of English Philology and Translatology, Daugavpils University, Latvia.
}

\begin{abstract}
The internationalisation of studies is one of the most current trends in higher education, aimed at improving the quality of higher education and preparing students for the global labour market. Student mobility is one of the most common forms of internationalisation. As part of the given study, an interview with the groups of exchange and local students at a regional university was conducted in order to clarify their views on the role of internationalisation in the educational process, general cultural literacy, promoting intercultural cooperation and building a global world view. The study took place in a bachelor's degree-level programme at a regional university in Latvia, using the qualitative method. A thematic analysis of the interviews was undertaken using an iterative, inductive approach to the generation of codes and themes. Coding was established using NVivo 12. In general, the internationalisation of studies (particularly student mobility) was evaluated very positively by both local and exchange students. The advantages of internationalisation are associated with the possibility of obtaining specific cultural expertise and learning life-friendly soft skills. In the future, the respondents see themselves employed in international teams taking as an advantage the experience gained in the internationalisation process. In addition, exchange students pointed out that the mobility experience specified in Curricula vitae could be considered by an employer as added value thus enhancing the opportunities to get a better job.
\end{abstract}

Keywords: internationalisation of studies; cultural literacy; incoming mobility; exchange student; regional university. 


\section{Introduction}

The globalisation of the modern world has led to the intensification of international contacts, which in its turn is associated with the shifts in cultural identity and the need to simultaneously recognise and disseminate one's cultural values, to be able to operate in the international cultural environment, as well as to be tolerant and knowledgeable with regard to other cultures. The rapidly evolving international labour market demands not only highly qualified specialists in a specific field but also multicultural workers. Globalization is defined by Altbach and Knight (2006) as the "economic, political, and societal forces pushing 21st century higher education toward greater international involvement" (p.1). The internationalisation of studies is one of the most effective ways of preparing the specialists required for the global labour market who can work in international teams.

The need for internationalisation is increasing, by changing university development strategies and turning national and regional universities into global educational institutions. Rizvi (2001) writes that "a global university must now be characterised by its engagement with the processes of globalisation, its international networks and its internationalized curriculum. The field of international education has matured in recent years, with the greater recognition of how it uniquely spans the cultural, economic and interpersonal dimensions of global relations" (para 3).

Although there is no single common definition for the internationalisation of higher education, the EU's (Bologna Declaration, Lisbon Strategy, EU 2020) strategic orientations for education policy and the growing international nature of higher education point to the need to build a common knowledge-based society. In recent years internationalisation awareness has grown significantly from initially the outgoing mobility of students and academic staff to a comprehensive approach in higher education, including international and intercultural dimensions into the course of studies (Beelen \& Jones, 2015). Higher education professionals consider that today there is a need to reconsider study programmes by introducing internationalisation mechanisms, to meet new global-diversity learning needs (Woolf, 2007) and to create learning that is comparative, integrative, interdisciplinary, contextual, and global (Green, 2007).

Internationalisation covers the following areas: attracting exchange students and teaching staff, cooperation in the student and academic staff exchange, development of programmes in foreign languages (commonly English), international cooperation in science, development of joint programmes and degrees, global research projects, etc. The added value of internationalisation has the economic impact on the region and university concerned (Sweeney, 2019), as well as on the extension of students' cultural literacy, networking, culture awareness, and acceptance of cultural diversity, cosmopolitanism, promotion of social 
equality, etc. (Fielden, 2007; Foster, 2013; Hartwig et al., 2017; Knight, 2003; Sweeney, 2012).

One of the most common forms of internationalisation is student mobility. Due to some objective reasons regional universities often face a lack of incoming learning mobility; hence, it is successfully implemented in some individual study programmes. As part of the given study, the focus groups of exchange and local students were interviewed with the aim of finding out their views on the role of internationalisation in the educational process, general cultural literacy, promoting intercultural cooperation and building a global world view. The researchers point out that trends in globalisation and internationalisation, open information space, wide opportunities for mobility, and development of the Internet have changed a person's view on themselves and their place in the world (Romanovska, 2019). In this context, the present study has its focus on the way regional and global (international) cultural levels interact in the course of development of students' cultural and world perceptions. It was also important to identify how the internationalisation of studies, namely the incoming mobility experience, can influence students' views on building future careers in international teams. The findings of the study can be useful for building an international learning environment and improving cooperation between exchange and local students in higher education institutions.

\section{Methodology}

The study was conducted at the regional university in Latvia engaging foreign and local students enrolled in the Bachelor study programme "Philology". In order to carry out the tasks of the research a fieldwork strategy was developed and the questions of a partly structured interview were formulated. It envisaged commencing work on October 1, 2019 and finishing it on December 20, 2019. When selecting respondents, the "theoretical sampling" (Breuer et al., 2019) approach was employed. The main method of the research is a qualitative method, namely, focus group interview. To ensure free exchange of opinions it was decided to conduct separate focus group interviews with the local and exchange students, respectively. In total, six focus group interviews were conducted: four interviews with the local students, and two interviews with the exchange students. The total number of the respondents was 20 people, of which 13 were girls and seven boys aged 20 to 24 . The exchange students who participated in the interview come from France, Italy and Turkey. The fieldwork was carried out by two researchers, and the interviews were conducted in Latvian, English, and Russian. The local students preferred to speak Latvian or Russian, but exchange students English.

The interviews were fully transcribed in the respective languages. A thematic analysis of the interviews was undertaken using an iterative, inductive approach to the generation of codes 
and themes. Coding was established using NVivo 12 for qualitative data analysis. To create initial codes, two reviewers independently read one interview, results were compared, and agreed codes were developed through discussion to create a coding matrix. Further coding was performed by one researcher.

\section{Student mobility as a way of improving cultural literacy}

\subsection{Evaluation of the incoming student mobility from the point of view of local students}

The students of the regional university who took part in the interview acknowledged that internationalisation is an important aspect of study, which contributes not only to successful acquisition of different courses but also promotes the development of the skills needed for life and provides sufficient cultural expertise. In general, students' experience communicating with foreigners was evaluated as successful. They appreciate such an opportunity and willingly engage in conversations with exchange students. The respondents described their attitudes to other cultures and nations as positive or neutral. Many students feel delighted having foreign students in the city, moreover, they feel happy about their studies at university, as this provides them with the opportunity to get communication experience that cannot be otherwise achieved. Moreover, the communication experience with exchange students was regarded by the students as more important than their own studies. The respondents emphasised that it is of utmost importance to consider the cultural knowledge which they can acquire when communicating with foreigners directly.

According to the respondents, the study environment opens way to easier communication with exchange students. It makes communication more open, safer, allows conversation to be opened easily, as well as determining the topics for further discussions. To open a conversation with exchange students in the university is relatively easy, commonly it happens during a break time, when discussing a particular study task. The respondents pointed out that they do not waste time on general questions such as "How are you?" etc., but rather focus on specific topics of their interest. Studies make the main topic of conversation, which gives an opportunity to enter into further discussion and develop informal relations outside the study environment.

The motivation to communicate with exchange students is determined by two factors: (1) ambition to learn English better (the respondents have admitted that the level of English knowledge in exchange students is generally better than in local students) and (2) ambition to learn more about one particular culture, represented by an exchange student.

In the course of the study process, academic staff pay special attention to the successful cooperation between exchange and local students; for example, by organizing mixed work groups (where there is one or two exchange students and several local students), providing a 
mentorship (addressing a particular student(s) with a request to explain specific educational and cultural realia to another student.) etc. It is noteworthy that the respondents did not notice that the academic staff were working deliberately and purposefully on the development of networking between local and exchange students. It means that they see such cooperation promoting strategy as perfectly comfortable and appropriate. The students were delighted with exchange students in their work group because they were forced to discuss particular topics in English, not in their native language. And it provides for other advantages: (1) there is a broader understanding of a particular topic, owing to the fact that exchange students express the ideas, which are determined by their affiliation with their own (different for local students) culture and different cultural literacy; (2) there is an opportunity to practise English. Local students pointed out that they are trying to do their best to make exchange students feel involved and comfortable, by interpreting jokes, explaining incomprehensible cultural realia, etc.

Extra curriculum activities such as Halloween party, Christmas Celebration, Fukshu Ball, etc. were reported by the respondents as the most successful forms of cooperation between local students and exchange students. Students admitted that these events allow them to develop informal relations, yet the most important topic of conversation remains the studies.

The respondents emphasized that they recognise many worthy features in exchange students they would like to learn or take over. These features are not limited to language or culturespecific knowledge. They are related to foreigners' perception of life in general. The respondents pointed out that one of the positive features of exchange students is a constructive way of thinking focused on problem solving. In contrast, local students often tend to focus on the problem itself, thus creating a pessimistic world view. Thus both a positive global approach and the ability to assess a situation from different perspectives can be considered advantages of internationalisation of studies.

The respondents acknowledged that their worldview, including the perception of foreigners, is determined by lifestyle in a small regional city. To give an example, although in general the attitude towards exchange students is "very positive", "rather positive" or "neutral", it may, however, be "reserved" towards representatives of certain cultures (Muslims, Arabs) until the person is seen closer. Such attitude, according to the students, is determined by the "specific nature of regional life", which is characterised by fears of everything alien and unwillingness to expand one's outlook.

\subsection{Exchange students' opinion on student mobility}

Internationalisation as a main issue suggested for the interview discussion arosed great interest among the exchange students, respondents of the second focus group in the given study. From the first minutes of the interview it was evident that the students were open to discussion and ready to share their opinion with much enthusiasm. 
For the major part of the focus group participants it was their first experience of student mobility, though it does not signify that they had a lack of expertise in international communication. Some of the respondents referred to their active involvement in joint projects and other activities back home when they were forced to cooperate with representatives of different cultures. They also gave feedback on receiving exchange students at their home universities. In both cases they evaluated that experience very positively, pointing to fruitful international communication. The latter explains the range of their expectations from the present mobility: to meet new people, learn new cultures and places, get new study experience and develop language skills.

They described their attitude to other cultures and internationality very positively, not differentiating between nations, religions etc. However, they described some cases, gained from the present mobility, when cultural illiteracy could lead to curious situations, even offence. Thus, they concluded, one should be aware of cultural differences when communicating in international environments.

In their reports they specified some particular personal traits that can promote successful communication. Friendliness and openness play the most important role in promoting internationalisation in students' cultural literacy and intercultural communication.

The choice of mobility location, in favour of a small regional university, was determined by the admission criteria set by the host universities; the submitted applications had been rejected by some universities as not complying with some programme criteria, namely academic performance. So, the students had not much choice but to accept invitation from a more flexible university. Surprisingly, a small regional high school turned as an advantage; flexibility is determined by the need to bring more incoming mobilities which is a characteristic feature of all regional high schools.

The respondents confirmed that they were more than satisfied with the study programmes and study environment provided by the host university. In contrast to their home universities, studying in small groups showed many advantages, ensuring a more individual approach and exchange of information between local students, exchange students and academic staff. It proved very advantageous for language learners, e.g. English as a language of intercultural communication.

Students noticed that in most cases the academic staff were very effective in promoting successful cooperation between local and exchange students. If the topics suggested for discussion by the academic staff in the classroom were in students' competence, communication turned out to be very successful. Exchange students echoed the local students in that the studies serve the starting point for developing communicative network in a multinational environment. 
It was also revealed that exchange students anticipated more initiative from the locals. They would appreciate more attention to their needs; for example, they expected to be introduced to the local culture and environment by the locals. The respondents did not face any difficulty when in the city; however, their contact with the people from the city was limited.

Similar to the local students, the foreign students also agreed that they observed some cultural peculiarities of the regional city, such as relatively passive social and cultural life, students' passivity, peculiar features of national character such as restraint, a lack of cafes and clubs where students might spend their time communicating with the locals, etc. The said features were evaluated by the foreign students negatively. As to language, language was not a barrier for any communication with the locals.

In contrast, the positive features of a small regional city include the following ones: a small university with easy-to-orientate environment, small groups of students, which provides much easier communication between the academic staff and students, as well as promoting better knowledge acquisition. Moreover, student mobility is a great opportunity to travel to different countries, the opportunity that is given only once in a life, as attested by all respondents. Whatever the experience, the respondents admitted that the mobility experience opens new gateways for future career, broadens one's outlook and develops people's cultural literacy. Student mobility mentioned in their CVs, they believe, adds value to their prospects.

\section{Conclusion}

The internationalisation of studies at a regional high school has its own features, which are related to both the number of foreign students and their level of knowledge, as well as to the peculiar life style of the regional city, which also shapes the outlook of the population. However, these regional features under the impact of globalisation tend to decline wherein the internationalisation processes facilitate this reduction.

Promotion of cooperation between local and foreign students at university is implemented in a variety of ways. The formal study environment provides mixed groups and introduces a mentoring system for recently arrived students. With regard to non-formal events, students have the opportunity to strengthen relationships by finding new topics for discussion and implementing joint projects.

To sum up, the internationalisation of studies (particularly student mobility) has high positive evaluation by both local and foreign students. The respondents' opinions on the gained advantages largely coincide. The advantages of internationalisation are associated with the possibility to obtain specific cultural expertise and acquire life-friendly soft skills. The respondents pointed out that by contacting representatives of other cultures, they improve their English language skills and broaden their general cultural literacy, which will be useful 
in their future life. Moreover, they learn to work in international teams and learn how to open communication with unfamiliar or little-known people, think broader, take a constructive approach to problem solving, and build positive world views. The foreign students highlighted another significant advantage that was not specified by the local students: it is not only the experience and knowledge gained through mobility that matters, but rather a reference to the mobility specified in their Curriculum vitae. It helps them to find a better job in the future. It is noteworthy that the majority of the respondents spoke about their ambition to work in international teams in the future and take advantage of the experience gained in the internationalisation of studies. It means that the internationalisation of studies is successful; students in the international environment feel comfortable and see prospects for further development.

\section{References}

Altbach, P.G., \& Knight, J.K. (2006). The internationalization of higher education: Motivations and realities. The NEA 2006 Almanac of Higher Education. Retrieved from http://www.nea.org/assets/img/PubAlmanac/ALM_06_03.pdf.

Beelen, J., Jones, E. (2015). Redefining Internationalization at Home. In: Curaj. Adrian et al. (Eds.) (2015). The European Higher Education Area Between Critical Reflections and Future Policies. Springer Open, Heidelberg New York, Dordrecht London, p. 59-72.

Breuer, F., Muckel, P., Dieris, B., Allmers, A., (2019). Reflexive Grounded Theory: eine Einführung für die Forschungspraxis, 4th, durchgesehene und aktualisierte Auflage ed, Lehrbuch. Springer VS, Wiesbaden.

Fielden, J. (2007). Global Horizons for UK Universities. London: The Council for Industry and Higher Education.

Foster, C. (2013). Genuine multiculturalism: The tragedy and comedy of diversity. Montreal, CA: McGill-Queen's University Press.

Green, M. F. (2007). Internationalizing community colleges: Barriers and strategies, New Directions for Community Colleges, 138, 15-24.

Hartwig, K., Barton, G., Bennett, D., Cain, D., Campbell, M., Ferns, S., Jones, L., Joseph, D., Kavanagh, M., Kelly, A., Larkin, I., O’Connor, E., Podorova, A., Tangen, D., \& Westerveld, M. (2017). What does internationalisation or interculturalisation look like in the future in the higher education sector? In G. Barton, \& K. Hartwig (Eds.), Professional learning in the work place for international students: Exploring theory and practice (pp. 313-320). Cham, Switzerland: Springer.

Knight, J. (2003). Apdating the definition of internationalization. International Higher Education. 33.

Programmas Erasmus plus valdīnijas, (2017). Retrieved from: https://ec.europa.eu/programmes/erasmus-plus/sites/erasmusplus2/files/2017-erasmusplus-programme-guide-v2 lv.pdf)

Rizvi, F. (2001). Internationalisation of curriculum. RMIT University: Melbourne. Retrieved from http://www.eotu.uiuc.edu/events/RIZVIPaperInternatRMIT.pdf 
Romanovska, A. (2019). The Search for Regional Identity: Latgale in Latvian Literature in the First Decades of the 20th Century. Forum for World Literature Studies, 11 (1), 39-62.

Sweeney S. (2019). Adapting conventional delivery to cope with large cohorts: turning seminars into workshops and changing assessment. 5th International Conference on Higher Education Advances (HEAd'19), 1059-1068. DOI: http://dx.doi.org/10.4995/HEAd19.2019.9505

Sweeney, S. (2012). Going Mobile: Internationalisation, mobility, and the European Higher Education Area. York: Higher Education Academy. Retrieved https://www.heacademy.ac.uk/system/files/resources/going_mobile.pdf.

The Bologna Declaration. (1999). Retrieved from http://www.magnacharta.org/resources/files/BOLOGNA_DECLARATION.pdf

The Europe $2020 \quad$ Strategy. (2010). Retrieved from https://ec.europa.eu/eu2020/pdf/COMPLET\%20EN\%20BARROSO $\% 20 \% 20 \% 20007 \%$ 20-\%20Europe\%202020\%20-\%20EN\%20version.pdf

The Lisbon Strategy. (2010). Retrieved from http://www.europarl.europa.eu/document/activities/cont/201107/20110718ATT24270/2 0110718ATT24270EN.pdf

Woolf, M. (2007). Impossible things before breakfast: Myths in education abroad. Journal of Studies in International Education, 11(2-3), 496-509. 